\title{
Videoessäer som pedagogisk metod för att utveckla medie- och informationskunnighet
}

\author{
Emil Stjernholm \\ Lunds universitet
}

\begin{abstract}
Denna reflektion handlar om hur videoessän, som ett alternativ till mer traditionella examinationsformer, kan bidra till att utveckla studenters medie- och informationskunnighet. Videoessäns funktion i film- och medievetenskaplig utbildning presenteras. Därefter diskuteras det pedagogiska upplägget för kursen där videoessän ingick som examinationsmoment. En slutsats är att videoessän är en examinationsform med potential inte enbart inom film- och medievetenskapen, utan inom många humanistiska och samhällsvetenskapliga ämnen. Formatet är dock behäftat med utmaningar. Medan en del studenter omfamnade formatet och tyckte det var utvecklande att analysera och argumentera i rörlig bild, ansåg andra studenter att det var ovant att uttrycka sig på detta vis och efterlyste mer stöd till de praktiska momenten i filmproduktionen.
\end{abstract}

Nyckelord: videoessä, teori och praktik, medie- och informationskunnighet

Medier utgör en central del av människors vardagsliv och från morgon till kväll omgärdas vi av information i olika mediala former. Medie- och informationskunnighet framstår idag som en nyckelkompetens för alla, såväl gamla som unga. Centralt handlar medie- och informationskunnighet, skriver Statens medieråd, om att "förstå mediers roll i samhället", "kunna analysera och kritiskt värdera information" samt att "själv kunna uttrycka sig och skapa innehåll i olika medier" ("Vad är MIK?", 202I). De senaste årens diskussioner om alternativa fakta, falska nyheter och desinformation har vidare aktualiserat vikten av att kritiskt granska medier i förhållande till olika samhälleliga och kulturella processer. En undervisnings- och examinationsform som har växt i popularitet de senaste åren är den så kallade videoessän (video essay). Som ett komplement till traditionella undervisningsmetoder, menar vissa forskare, kan videoessäer främja studenters medie- och informationskunskap (Mcwhirter, 20I5). Precis som skriftliga uppsatser kan videoessän användas för att presentera en analys, men till skillnad från dessa utnyttjar videoessän filmens språk för att synliggöra och främja argumenten. Som medieteoretikern Lev Manovich argumenterar kan det framstå som onaturligt att använda språk och skriven text för att beskriva estetiska fenomen, om det så handlar om färger, ljudsättning eller klippning (2020: 157). I videoessäer kombineras alltså olika modaliteter - som ljud, bild och text - för att föra fram budskap eller framföra ett argument. Om det tidigare var dyrt och otillgängligt för studenter att arbeta med rörlig bild finns idag videoredigeringsprogram fritt tillgängliga på nätet och många avancerade verktyg finns till och med tillgängliga i våra mobiltelefoner.

Denna text handlar om videoessän som pedagogisk metod för att utveckla studenters medieoch informationskunnighet. Artikeln består av en kort bakgrundsdel om studiet av film efter

*Författarkontakt: emil.stjernholm@kom.lu.se 


\section{Emil Stjernholm}

den digitala vändningen, en litteraturöversikt om videoessän som format och genre samt en reflektion om hur videoessäer fungerar i klassrummet i praktiken. I texten utgår jag ifrån mina erfarenheter som lärare på kursen Media and Representation inom ramen för kandidatprogrammet i medie- och kommunikationsvetenskap vid Malmö universitet, en kurs där praktiska och teoretiska kunskaper sammanflätades. I denna kurs användes videoessän som examinationsform i kombination med en individuell skriftlig reflektion. Medan en del studenter omfamnade formatet och tyckte det var utvecklande att analysera och argumentera i rörlig bild, ansåg andra studenter att det var ovant att uttrycka sig på detta vis och efterlyste mer stöd med de praktiska momenten i filmproduktionen. Med utgångspunkt i dessa konkreta undervisningserfarenheter pekar denna reflektion såväl på videoessäns förtjänster som potentiella problem.

\section{ATT STUDERA FILM EFTER DEN DIGITALA VÄNDNINGEN}

Under det senaste decenniet har filmen gått igenom en teknologisk transformation där celluloid ersatts av digitala teknologier inom produktion, distribution och reception. Redan 2012 beskrev filmteoretikern David Bordwell i en lika uttömmande som analytiskt träffsäker bloggpost övergången från analog till digital film som en osynlig revolution. Medielandskapets snabba förändringar, menar Bordwell, har haft en stor inverkan på filmvärlden—från Hollywoods digitala produktionsflöde till den blomstrande scenen för nollbudgetproduktioner, från de stora kommersiella biografkedjornas tekniksatsningar till det växande antalet streamingjättar som Netflix, Amazon Prime och Hulu som utmanar de traditionella auktoriteterna. Hemmatittandet har ökat och utbudet av såväl film som TV-serier tillgängliga för omedelbar konsumtion har exploderat. Samtidigt som biograffilmens nedgång har beskrivits som en kris för filmbranschen konsumerar vi paradoxalt nog mer rörlig bild än någonsin. Exempelvis skriver Cisco, ett amerikanskt datakommunikationsbolag, att video utgör $8 \mathrm{I} \%$ av den amerikanska internettrafiken år 202I (Cisco, 202I). Med andra ord har filmmediet genomgått en digital omvälvning, varpå gränserna för vad en filmforskare har som sitt primära studieobjekt har förskjutits från den narrativa biografvisade spelfilmen till en uppsjö av olika former av rörliga bilder som distribueras genom en rad olika plattformar.

Den digitala revolutionen har vidare gett upphov till att människors förhållande till rörliga bilder har förändrats. I sociala medier kommenteras, delas och remixas film och branschen ägnar denna form av deltagarkultur allt mer uppmärksamhet. Filmare idag arbetar med en annan palett än de gjorde förr, till exempel med nya former av animation och CGI (computer generated images), vilket påverkat filmens språk. Som många forskare har påpekat kan dagens visuella kultur beskrivas som en skärmkultur där mobiler, laptoppar och läsplattor utgör en naturlig del av många människors vardagsliv (Butsch, 2019). Som tidigare påpekats innebär den digitala revolutionen att film inte enbart visas på en uppsjö av olika plattformar, från iPhone till IMAXbiografer, utan även distribueras på olika sätt, från streaming till fildelning. Detta har medfört att konsumenten av rörlig bild idag är allt annat än passiv. Snarare visar fenomen som YouTube att konsumentrollen allt mer börjar smälta samman med producentrollen (Ritzer, Dean \& Jurgenson, 20I2). Medievetaren Julian McDougall menar att en stor fördel med medievetenskap (och närliggande akademiska discipliner som filmvetenskap) är att man kan "work with students on their own terms and genuinely learn from their interests and consumption" (2006: 4).

\section{VIDEOESSÄER OCH MEDIE- OCH INFORMATIONSKUNNIGHET}

För att förstå filmberättandets konventioner är det viktigt att tillskansa sig kännedom om filmanalytisk terminologi samt de narrativa och stilistiska komponenter som ibland kallas för filmens 
språk. Inom ett ämne som filmvetenskapen tenderar man att närstudera klassiska filmer som Alfred Hitchcocks Vertigo (1958), Stanley Kubricks 200I: A Space Odyssey (1971) eller Jonathan Demmes När lammen tystnar (199I). Studenterna uppmanas att bryta ner filmernas beståndsdelar och identifiera viktiga stilelement (se exempelvis Bordwell, 2006), inte sällan genom att man i klassrummet går igenom verket tagning för tagning. Sådana närläsningar fokuserar i regel på stil- och berättargrepp som tagningstyp, klippteknik, ljussättning samt filmens iscensättning (mise-en-scène), det vill säga kamerans rörelser, val av kameravinkel, hur bilden komponerats samt vilka bildutsnitt som görs. På så vis kan en förståelse skapas för berättande i rörliga bilder i en lång rad genrer och tidsepoker, från Hollywood till europeisk konstfilm, från dokumentärfilm till reality-TV, från reklamfilm till politisk propaganda.

Även om professionella filmskapare och forskare länge har arbetat med videoessäer är det först under de senaste åren som formatet har utkristalliserat sig som en betydelsefull pedagogisk metod för att fördjupa studenters kunskap om filmberättande. Formatets popularitet märks bland annat genom att en akademisk tidskrift, [in]Transition, lanserats som helt ägnas åt referentgranskade videoessäer. Ett annat exempel är omtyckta YouTube-kanaler som Every Frame a Painting, som lanserades 20I4, och Lindsay Ellis Nostalgia Critic som lanserades 20I5 och som inriktar sig på att studera filmens språk med hjälp av rörliga bilder. Filmvetarna Thomas van den Berg och Miklós Kiss (2016) argumenterar för att flera videoessäisiska underkategorier eller genrer har etablerats under senare år - från mer traditionella illustrerade föreläsningar till mer främmandegörande, experimentella videoessäer. Som Eric S. Faden har belyst kan videoessän även främja forskares och studenters medie- och informationskunnighet: "The scholar must consider ideas of image, voice, pacing, text, sound, music, montage, rhythm ... by grappling with these problems first hand, scholars instantly improve their critical and teaching skills. Quite simply, once you make a movie (or attempt to do so), you never look at another film the same way again” (2008: 4). Andra videoessäister framhåller det personliga, essäistiska tilltalet som en fördel gentemot den traditionella textpublikationen (Grant, 20I2).

Samtidigt kan man argumentera för att många av de miljontals videor som dagligen laddas upp på YouTube eller TikTok är videoessäer i någon mening, och många använder "filmens språk" i vardagen. I antologin Educating the Net Generation har Diana G. Oblinger och James L. Oblinger undersökt hur man kan förstå vad de kallar "the Net Generation", det vill säga människor som växt upp med internet-tillgång, och deras lärande (2005). Artikelförfattarna påpekar att dagens ungdomar är "digitally literate" vilket innebär att "The Net Gen are more visually literate than previous generations; many express themselves using images. They are able to weave together images, text, and sound in a natural way. Their ability to move between the real and the virtual is instantaneous, expanding their literacy well beyond text" (2005: 16). Så kan man till exempel utifrån Kolbs lärandemodell (1983) argumentera för att videoessän går ut på att integrera teori och praktik, det vill säga att få studenterna att använda de teoretiska kunskaper och färdigheter de tidigare förvärvat och applicera dessa i ett praktiskt sammanhang.

För att mer konkret exemplifiera hur videoessän kan användas vid filmanalys kan man vända sig till medie- och kommunikationsvetaren Jason Mittells arbete med formatet. Sedan 20 I2 har Mittell publicerat ett sjuttiotal videoessäer via sin egen Vimeo-kanal. En videoessä som illustrerar formatets förtjänster är How Black Lives Matter in The Wire (2018) i vilken han analyserar HBO:s kriminaldrama The Wire (David Simon, 2002-2008) i relation till samtida (filmade) vittnesmål om polisbrutalitet mot svarta i USA. TV-serien utspelar sig i den fattigdomstyngda staden Baltimore i nordöstra USA och följer såväl polisen som dem som lever i staden. Mittell påpekar i inledningen att det senaste decenniets tilltagande gräsrotsbevakning (sousveillance) - ofta 


\section{Emil Stjernholm}

med mobilkamerans hjälp - har kastat ljus över polisbrutaliteten mot svarta i landet. En rad uppmärksammade dödsfall har fångats på video, som fallen Eric Garner och Michael Brown och senare George Floyd, vilket har skapat debatt samtidigt som Black Lives Matterrörelsens protester växer. Även om den sortens videoupptagningar av polisvåld inte figurerar narrativt i The Wire, berättar Mittell, ger serien oss inblick i de strukturer som föder polisvåldet. I videoessän analyseras en nyckelsekvens där tre unga poliser bestämmer sig för att sända en signal genom att åka in i ett utsatt område nattetid och konfrontera "de kriminella". En närgången, skakig kamera visar hur en äldre man trycks upp mot väggen, men han har varken droger eller vapen på sig. På väg tillbaka till polisbilen noterar en av poliserna, Roland "Prez" Pryzbylewski, att en ung svart pojke sitter på motorhuven. Han stegar fram och slår honom hårt $\mathrm{i}$ ansiktet med sin pistol. Här använder sig Mittell av redigeringstekniken för att understryka den oprovocerade brutaliteten genom att visa sekvenser tre gånger i följd, samtliga gånger i slow motion. I videoessän ställs de dokumentära bilderna av polisvåld vid sidan om fiktionella exempel från TV-serien vilket gör kopplingarna kännbara inte bara analytiskt utan även känslomässigt. På liknande vis kan kopplingar mellan platser, återkommande teman eller stilistiska mönster åskådliggöras i videoessäformatet.

I dagsläget används videoessän i synnerhet som examinationsform inom filmvetenskap, medie- och kommunikationsvetenskap och inom konstnärliga utbildningar i syfte att analysera mediala representationer. Videoessän som examinationsform, det vill säga ett format och uttryck där rörlig bild, ljud, text och tal blandas, har dock vidare pedagogisk potential även inom andra ämnen. Ett exempel på hur videoessäer produktivt kan användas för att analysera annat än mediala representationer är YouTube-kanalen Vox. På denna kanal analyseras historiska skeenden, formuleras debattinlägg i aktuella samhällsfrågor och samhällsvetenskaplig och naturvetenskaplig forskning visualiseras. Det finns oräkneliga underkategorier och videoessäernas tematik spänner från frågeställningar som "Varför är det inbördeskrig i Etiopien?" och "Dessa fotografier skapade ett propagandakrig under kalla kriget" till "Varför dyker det upp så många covid-ı9 mutationer nu?".

Som tidigare har påpekats är det lättare än någonsin att arbeta praktiskt med rörlig bild. Idag finns det många guider och YouTube-tutorials som beskriver hur man kan arbeta med videoredigeringsverktyg i framställningen av videoessäer, däribland resursen The Audiovisual Essay (https://reframe.sussex.ac.uk/audiovisualessay) som erbjuder både "how to"-manualer och teoretiska reflektioner. Detta gör tröskeln till att inkludera praktiska filmmoment i undervisningen lägre. Samtidigt bör det påpekas att det faktum att videoessän inte tillhör de vanligaste examinationsformerna på svenska universitet (såsom hemtentor, salstentor eller skrivuppgifter) medför en potentiell svårighet för undervisande lärare. Exempelvis kan frågor uppstå om vilka krav man kan ställa på studenternas färdigheter när det kommer till produktionen av en videoessä kontra exempelvis skriftlig färdighet eller förmåga.

\section{VIDEOESSÄN SOM UPPGIFT}

Denna reflektion bygger på erfarenheter från undervisning på kursen Media and Representation som ges inom ramen för kandidatprogrammet i medie- och kommunikationsvetenskap vid Institutionen för konst, kultur och kommunikation $\left(\mathrm{K}_{3}\right)$, Malmö universitet. Under kursens gång undervisade kursansvarige tillsammans med en universitetslektor med stor erfarenhet av eget filmskapande. Kursen omfattade 7,5 högskolepoäng och gavs på helfart (2019). Kursen utformades av kursansvarig (författaren till denna reflektion) med en uttalad ambition att arbeta med konstruktiv länkning (Biggs \& Tang, 20II). De fem kursmålen formulerades på följande vis: 
Efter avslutad kurs ska studenten kunna:

- Beskriva och diskutera olika slags mediala representationer

- Beskriva och reflektera över sociala, teknologiska och kulturella perspektiv på mediala representationer

- Visa förmåga att analysera form och innehåll i mediala representationer

- Reflektera kritiskt kring mediala representationer utifrån genus-, etnicitets- och klassperspektiv

- Planera och genomföra en medieproduktion om mediala representationer

Arbetet med videoessän kopplades till samtliga fem ovan specificerade kursmål, dels fyra mer teoretiskt orienterade lärandemål, dels det femte lärandemålet som specifikt beskriver studenternas förmåga att planera och genomföra en medieproduktion om mediala representationer. Den första delen av kursen byggde på kurslitteratur av främst Stuart Hall (20I3) samt ett urval av nyare vetenskapliga artiklar om representation ur olika teoretiska perspektiv tillgängliga via universitetets databas. Efter halva kursen författades en kortare individuell medieanalys. Den andra delen av kursen innehöll två workshoppar med fokus på filmproduktion och tid för självständigt arbete med videoessäerna. För att stödja studenternas arbete anordnades även feedbackträffar där studenterna i halvklass diskuterade sitt pågående arbete med videoessäerna med lärarna. Kursen avslutades med en redovisning av filmprojektet samt en individuell skriftlig reflektion. Detta var det första tillfället under kandidatprogrammets gång som videoessä fungerade som en av examinationsformerna. I samband med att arbetet med videoessän påbörjades delades även betygskriterier ut. Dessa lade särskild tonvikt vid utförandet och presentationen av medieproduktionen, strukturerade och tydliga resonemang, detaljerade och reflekterande analyser och förmågan att koppla den egna analysen till aktuell kurslitteratur.

Stereotyper och representationer i medierna har varit ett centralt ämne inom många humanistiska och samhällsvetenskapliga ämnen under flera decennier. Det kan gälla könsstereotyper (Goffman, 1976), representationen av klass (Streib, Ayala \& Wixted, 20I7) eller olika etniciteter (Hall, 20I3). I den första delen av kursen låg tonvikten på teoretiska perspektiv för att skapa goda förutsättningar för reflekterande analyser i ämnet. Efter halva kursen påbörjades videoessäuppgiften som bestod av att studenterna i grupper om fyra eller fem personer fick analysera en valfri medial representation med utgångspunkt i kurslitteraturen. Under workshoppar, feedbacksessioner och den avslutande redovisningen fick studenterna kommentera varandras arbete med utgångspunkt i de specificerade betygskriterierna. Under dessa tillfällen var lärarna delaktiga som samtalspartners. I samband med dessa workshoppar diskuterades även upphovsrättsrätten, som ser olika ut i olika länder. I en svensk kontext regleras användandet av upphovsrättsskyddat material av citaträtten som täcker bland annat litteratur, musik och film (däremot inte konst för vilket det finns särskilda regler). "Var och en får citera ur offentliggjorda verk i överensstämmelse med god sed och i den omfattning som motiveras av ändamålet”, lyder lagtexten. Den centrala bedömningsfrågan handlar om citatets syfte, det vill säga om författaren använder andras verk självständigt för att skapa någonting nytt. En annan viktig bedömningsfråga gäller citatets omfattning, det vill säga ett citat făr endast göras i den omfattning som är motiverat av ändamålet. I detta fallet offentliggjordes aldrig videoessäerna utan de gjordes endast i utbildningssyfte.

Uppgiften var fritt formulerad och de ramar som presenterades var i synnerhet teknologiska snarare än tematiska (exempelvis val av videoformat och längd på videoessän). Studenterna valde olika ingångar till uppgiften och flera olika perspektiv på fenomenenet medier och representation. Några grupper valde att göra korta traditionella dokumentärfilmer med intervjuer 


\section{Emil Stjernholm}

("talking heads"), berättarröst samt dokumentära mellansekvenser studenterna spelat in själva. Tematiskt behandlade dessa dokumentärfilmer till exempel den mediala gestaltningen av damfotboll och stereotypa myter och fördomar mot romer. För dessa studenter gjordes merparten av arbetet på fältet, medan andra grupper gjorde merparten av arbetet i videoredigeringsverktyget. Flera av dessa grupper valde att göra montageklippta videoessäer där berättarrösten, med utgångspunkt i ovan diskuterade teoretiska perspektiv, analyserade de rörliga bilderna. Exempelvis valde några studenter att analysera representationen av svenskar i amerikansk film och television, med otaliga exempel på hur blonda svenska kvinnor sexualiseras i filmer som Dum och dummare (Peter och Bobby Farrelly, 1994) och Out Cold (Emmett och Brendan Malloy, 20II), ett fenomen som kan härledas till "den svenska synden" som fick ett stort genomslag i Nordamerika under 1960- och 1970-talen (Björklund \& Larsson, 2016). I de montageklippta videoessäerna bidrog valet av scener till att synliggöra argumentet även visuellt. Examinationen genomfördes gemensamt av kursansvarige (författaren) och den undervisande universitetslektor som också arbetade med kursen i relation till de specificerade betygskriterierna. I samband med examinationen bedömdes även den individuella skriftliga reflektion som varje student som varit involverad i medieproduktionen också hade skrivit, något som är viktigt ur ett rättssäkerhetsperspektiv för att säkerställa den invididuella bedömningen.

\section{STUDENTERNAS PERSPEKTIV}

Med utgångspunkt i den kursvärdering som genomfördes efter avslutad kurs är det möjligt att ta del av studenternas synpunkter. Malmö universitet använder sig normalt av en digital lösning där kursvärderingarna är utformade på ett standardiserat vis. Eftersom det handlade om en kurs med ett nytt pedagogiskt upplägg och en experimentell examinationsform valde kursansvarige att utforma en analog kursvärdering med mycket utrymme för fritextsvar. En fråga med fritextsvar behandlade specifikt videoessän som pedagogiskt verktyg. Utöver detta bestod kursvärderingen av slutna frågor med förutbestämda svarsalternativ med en sexgradig skala ( $\mathrm{I}=$ mycket dåligt, $6=$ mycket bra). Kursvärderingen besvarades av I8 studenter av totalt 38 inskrivna på kursen $(47 \%)$. Studenternas helhetsintryck var gott $(4,6)$. Studenterna var också generellt nöjda med kursens examinationsformer och möjligheten att visa att de uppnått lärandemålen $(4,8)$. Fritextsvaren på frågan om examinationsformen ger en mer nyanserad bild med både positiva och negativa upplevelser. Bland de positiva omdömena märks kommentarer som "Gillade filmskapandet" och "Jag gillar att arbeta praktiskt \& med dokumentärfilmen fick jag ta del av det vilket var roligt". En annan student uttryckte det på följande vis: "Det kändes som att man fick en väldigt praktisk möjlighet att använda sig av allt man lärt sig." Ytterligare en student lyfte fram blandningen av teoretiska och praktiska perspektiv: "Uppskattade variation med teoretiskt och praktiskt."

Utifrån dessa reflektioner om examinationsformen tycks det som att det praktiska momentet understödde vissa studenters förmåga att reflektera kritiskt kring mediala representationer utifrån diverse teoretiska perspektiv. Formatet underlättade även för studenterna att ge fler empiriska exempel i sina analyser av stereotypiska representationer, då ett större antal filmklipp i en snabb montagesekvens - exempelvis med bilder av hur svenska blondiner porträtteras i amerikansk Hollywood-film - tar upp betydligt mindre analytiskt utrymme i rörlig bild än $i$ en skriftlig analys. Ur detta perspektiv tillåter videoessän studenten att ägna mer tid åt de analytiska och teoretiska perspektiven. Bland fritextsvaren märks samtidigt en del kritik och förslag på förbättringar. Exempelvis efterlyste flera studenter ytterligare stöd i filmproduktionsarbetet. En student formulerade det på följande vis: "När man sen tidigare har noll erfarenhet 
av videoredigering så begränsar det gruppen väldigt mycket." En annan student pekade på att mindre grupper än fyra eller fem personer hade föredragits då det hade underlättat för att "dela upp ansvaret". Fritextsvaren pekar också på en upplevd obalans mellan studenterna gällande deras förkunskaper när det gäller användningen av videoredigeringsverktyg, något som hade en tendens att påverka grupparbetet negativt.

\section{SLUTSATSER}

Videoessän är en examinationsform med potential inte enbart inom film- och medievetenskapen utan inom många humanistiska och samhällsvetenskapliga ämnen. För att summera så pekar denna text på flera användningsområden. Inom filmvetenskapen har formen använts främst för att analysera filmiskt berättande. Inom medie- och kommunikationsvetenskap, och inom ramen för vår kurs, stod mediala representationer i centrum. Samtidigt kan man argumentera för att videoessän har en bredare pedagogisk potential inom humaniora och samhällsvetenskap. Dels har den nya studentgenerationen vuxit upp i ett samhälle präglat av visuellt berättande, exempelvis via YouTube, TikTok och Instagram, dels lämpar sig formatet sig väl för att analysera, debattera och visualisera samhällsfrågor generellt, vilket exemplet Vox pekar på. Ytterligare ett viktigt pedagogiskt argument är att studenterna får möjlighet att träna sin egen medie- och informationskunnighet genom att de själva får producera video och lära sig att argumentera med hjälp av rörliga bilder.

Under kursen Media and Representation visade studenterna god förmåga att reflektera och diskutera medierepresentationer samt att producera filmer som kritiskt analyserar representationer. Denna blandning av teoretiska och praktiska perspektiv framhålls i tidigare forskning som central för att främja medie- och informationskunnighet. Av kursvärderingarna går det att dra lärdomar inför liknande framtida experiment med videoessäer som examinerande moment. En sak som efterlystes var ytterligare handledning och feedback för att understödja arbetet med videoessän. I detta fall hade två workshoppar samt ett feedbacksamtal schemalagts. Därutöver bör det påpekas att ett antal studenter inte upplevde att de var bekväma med att uttrycka sig i videoessäformatet. Medan vissa menade att videoredigeringsverktygen var svårhanterliga, ansåg andra att de var osäkra på sin förmåga att skapa en kvalitativ videoessä. Ett sätt att hantera denna problematik är att arbeta med liknande praktiska moment även i andra kurser under en utbildnings gång. Ett annat alternativ vid liknande experiment kan vara att göra videoessän till en valbar examinationsform vid sidan om mer traditionella examinationsformer.

\section{FÖRFATTARPRESENTATION}

Emil Stjernholm är fil.dr i filmvetenskap och biträdande lektor i medie- och kommunikationsvetenskap vid Institutionen för kommunikation och medier, Lunds universitet. Hans undervisningsområden omfattar exempelvis medieteori, visuell kommunikation och mediehistoria. Hans forskning inriktas bland annat på filmen och televisionens historia, politisk propaganda samt digitala metoder.

\section{REFERENSER}

Biggs, J. \& Tang C. (2011). Teaching for Quality Learning at University: What the Student does. Maidenhead: Open University Press.

Björklund, E. \& Larsson, M. (2016). Swedish Cinema and the Sexual Revolution. Jefferson: McFarland. Bordwell, David (2012). Pandora's digital box: From films to files. Observations on Film Art: http://www. davidbordwell.net/blog/2012/02/28/pandoras-digital-box-from-films-to-files/, hämtad 2021-07-12. Butsch, R. (2019). Screen Culture: A Global History. Cambridge: Polity. 


\section{Emil Stjernholm}

Cisco. (2021). VNI Complete Forecast Highlights, https://www.cisco.com/c/dam/m/en_us/solutions/ service-provider/vni-forecast-highlights/pdf/United_States_2021_Forecast_Highlights.pdf, hämtad 2021-10-04.

Faden, E. (2008). A Manifesto for Critical Media. Mediascape. www.tft.ucla.edu/mediascape/Spring08_ ManifestoForCriticalMedia.html, hämtad 2021-07-03.

Goffman, E. (1976). Gender Advertisements. New York: Harper and Row.

Grant, C. (2012). Film and moving image studies. Re-born digital? Some participant observations. Frames cinema journal, 1: 1, 1-20.

Hall, S. (2013). Representation. London: Sage.

Kolb, D. A. (1983). Experiential Learning: Experience as the Source of Learning and Development. Englewood Cliffs: Financial Times/Prentice Hall.

Manovich, L. (2020). Cultural Analytics. Cambridge: MIT Press.

McDougall, J. (2006). The Media Teacher's Book. London: Hodder Arnold.

Mcwhirter, A. (2015). Film Criticism, Film Scholarship and the Video Essay. Screen, 56: 3, 369-377. https://doi.org/10.1093/screen/hjv044

Oblinger, D. G. \& Oblinger, J. L. (2005). Educating the Net Generation. Boulder: Educause.

Ritzer, G., Dean, P. \& Jurgenson, N. (2012). The Coming of Age of the Prosumer. American Behavioral Scientist. 56: 4, 379-398. https://doi.org/10.1177/0002764211429368

Statens medieråd. (2021). Vad är MIK?. Statens Medieråd: https://www.statensmedierad.se/mik-sverigeskunskapsbank/mik-sverige/vad-ar-mik publicerad 2021-02-11, hämtad 2021-07-06.

Streib, J., Ayala, M. \& Wixted, C. (2017). Benign Inequality: Frames of Poverty and Social Class Inequality in Children's Movies. Journal of Poverty. 21: 1, 1-19, https://doi.org/10.1080/10875549.2015.1112870

van den Berg, T. \& Kiss, M. (2016). Film studies in motion: From audiovisual essay to academic research video. Scalar. https://scalar.usc.edu/works/film-studies-in-motion/index, hämtad 2021-10-14. 